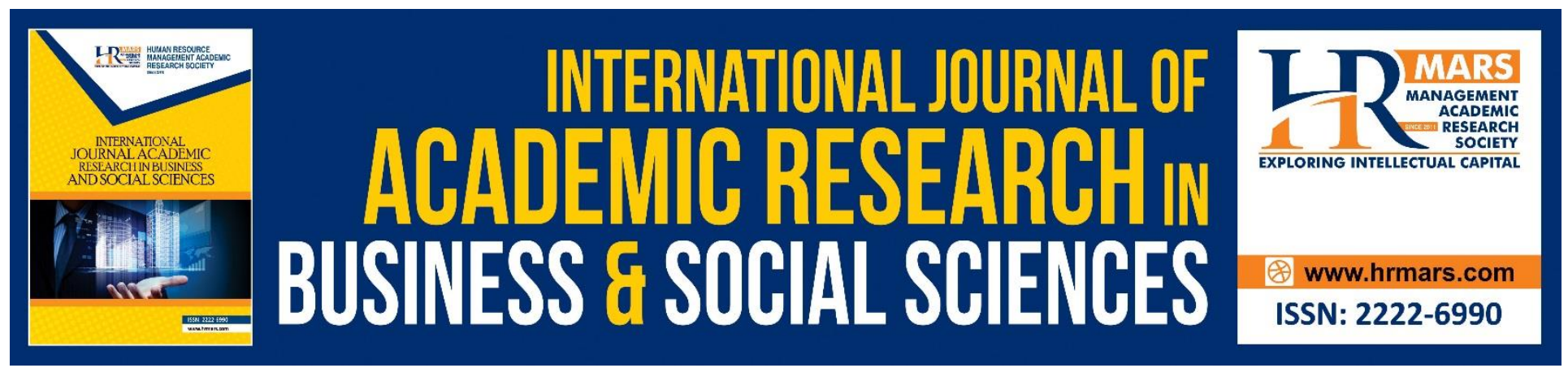

\title{
Forecasting Model for Organic Waste Generation at Administration Cafe in UiTM Tapah Campus
}

Faridah Zulkipli, Nurul Husna Jamian, Ilya Zulaikha Zulkifli

To Link this Article: http://dx.doi.org/10.6007/IJARBSS/v10-i9/7982

DOI:10.6007/IJARBSS/v10-i9/7982

Received: 03 August 2020, Revised: 27 August 2020, Accepted: 09 September 2020

Published Online: 29 September 2020

In-Text Citation: (Zulkipli, Jamian, \& Zulkifli, 2020)

To Cite this Article: Zulkipli, F., Jamian, N. H., \& Zulkifli, I. Z. (2020). Forecasting Model for Organic Waste Generation at Administration Cafe in UiTM Tapah Campus. International Journal of Academic Research in Business and Social Sciences. 10(9), 1023-1032.

Copyright: (C) 2020 The Author(s)

Published by Human Resource Management Academic Research Society (www.hrmars.com)

This article is published under the Creative Commons Attribution (CC BY 4.0) license. Anyone may reproduce, distribute, translate and create derivative works of this article (for both commercial and non-commercial purposes), subject to full attribution to the original publication and authors. The full terms of this license may be seen at: http://creativecommons.org/licences/by/4.0/legalcode

Vol. 10, No. 9, 2020, Pg. 1023 - 1032

Full Terms \& Conditions of access and use can be found at http://hrmars.com/index.php/pages/detail/publication-ethics 


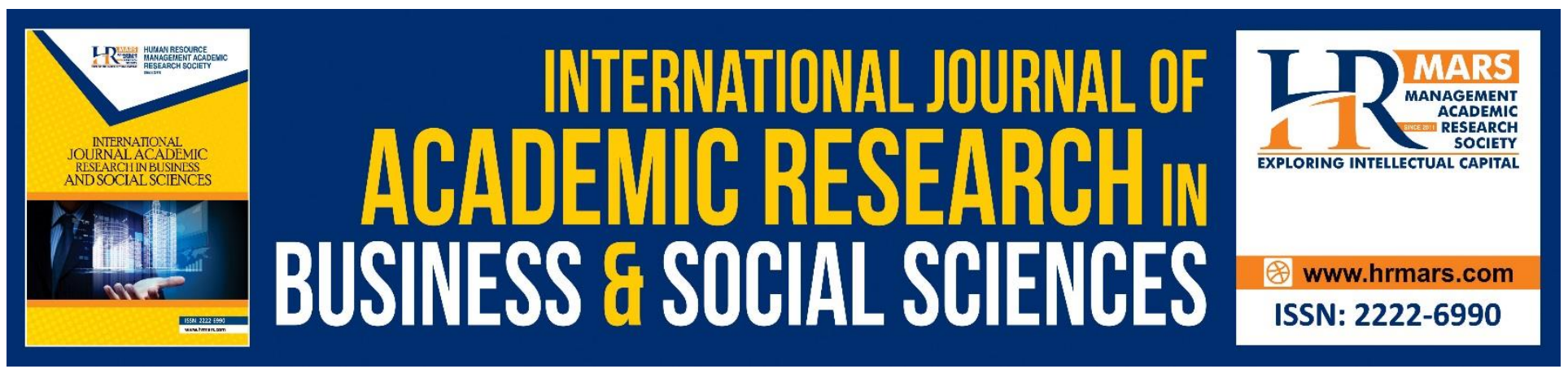

\title{
Forecasting Model for Organic Waste Generation at Administration Cafe in UiTM Tapah Campus
}

\author{
Faridah Zulkipli, Nurul Husna Jamian, llya Zulaikha Zulkifli \\ Faculty of Computer and Mathematical Sciences, Universiti Teknologi MARA, Perak Branch, Tapah \\ Campus, Tapah Road, 35400 Perak, MALAYSIA
}

\begin{abstract}
This study aims at analyzing, comparing and selecting the best predictive model based on organic waste generation at the UiTM Tapah Campus administration cafe. The data collection period begins Monday through Friday from 4th Mac 2019 until 20th April 2020. There are 2 bins that are labeled as Bin 1 and Bin 2 at the Administration Cafe on the UiTM Tapah Campus. Using the Risk Simulator Software, the Moving Average Model, Exponential Smoothing Model, and Holt-Winters Model were adapted and analyzed. The best model is chosen based on error compare meaning. There are three statistical errors in this study which are used for comparison purposes as RMSE, MSE, and MAD. As a result, the lowest error values for both Bin 1 and Bin 2 are shown on the Moving Average model. Therefore, the Moving Average Model can be concluded at Administration Cafe in UiTM Tapah Campus as the best equipped model based on current organic waste generation. The best model will be used in future at Administration Cafe in UiTM Tapah Campus to predict organic waste generation. Keywords: Waste Generation, Solid Waste Management, Forecasting Technique.
\end{abstract}

\section{Introduction}

Solid waste management is a necessary part of the business to protect the environment and to ensure sustainability and quality community life. Therefore, solid waste management is now considered as one of the global issues because everyone is responsible for the generation of solid waste produced every day (Zulkipli, et al. 2019). Increase in population, upgrade socio-economic and lifestyle changes are a major factor in raising the country's solid waste generation and change composition. The estimated domestic solid waste generation in 2018 capacity at Malaysia reaches 38,000 tons a day (SWCorp, 2019). This rate has been beyond the expectations of a study conducted by Japan The International Cooperation Agency (JICA) is 30,000 tons 2020. This scenario is a major issue for the country due to the increase solid waste generation will require a landfill larger one that will certainly increase the cost of waste management solid. Therefore, the public needs to learn methods of managing solid waste regularly or prospectively face the risks of environmental pollution and threats serious health in the future.

Malaysia is on the move implement effective strategies and initiatives in the aspects physical, economic and social towards a mission to be become a developed country. Accordingly, the level of 
INTERNATIONAL JOURNAL OF ACADEMIC RESEARCH IN BUSINESS AND SOCIAL SCIENCES Vol. 10, No. 9, 2020, E-ISSN: 2222-6990 @ 2020 HRMARS

cleanliness and environmental sustainability is one of the features that needs to be given attention. To achieve a level of cleanliness and environmental sustainability around the country, Malaysia faces many challenges needs to be addressed in a strategic and effective way. Challenge which is faced with various aspects including attitude and mind society, finance, technology, human resources and enforcement.

Pursuant to the Solid Waste and Public Waste Management Act 2007 (Act 672), solid waste is defined as any unwanted scrap or other excess or rejected product arising from the use of any process (Zulkipli, et al., 2017). There are 7 categories of solid waste under Act 672, which are household waste, industrial waste, construction waste, commercial waste, institution waste, imported waste and civil solid waste. This study is focused on institution waste which is organic waste. Organic waste can be classified as any material that is biodegradable and comes from either a plant or an animal. Biodegradable waste is organic material that can be broken into carbon dioxide, methane or simple organic molecules. For example, food waste, garden waste and green waste.

Based on waste composition in Malaysia, the organic waste generation contributes $50.3 \%$, which is the highest contribution besides $13.2 \%$ of plastics, $12.1 \%$ of diapers and sanitary napkins and $24.4 \%$ consist of paper, glass, textile, tetra pack and others. Figure 1 shows the waste composition in Malaysia (SWCorp, 2014). In 2012 shows the amount left over the solid produced in Malaysia in 2012 is estimated at 33,130 tons per day based on a population of 28.3 million people. While the rest food is the most generated waste, accounting for $45 \%$ of the total waste generated daily.

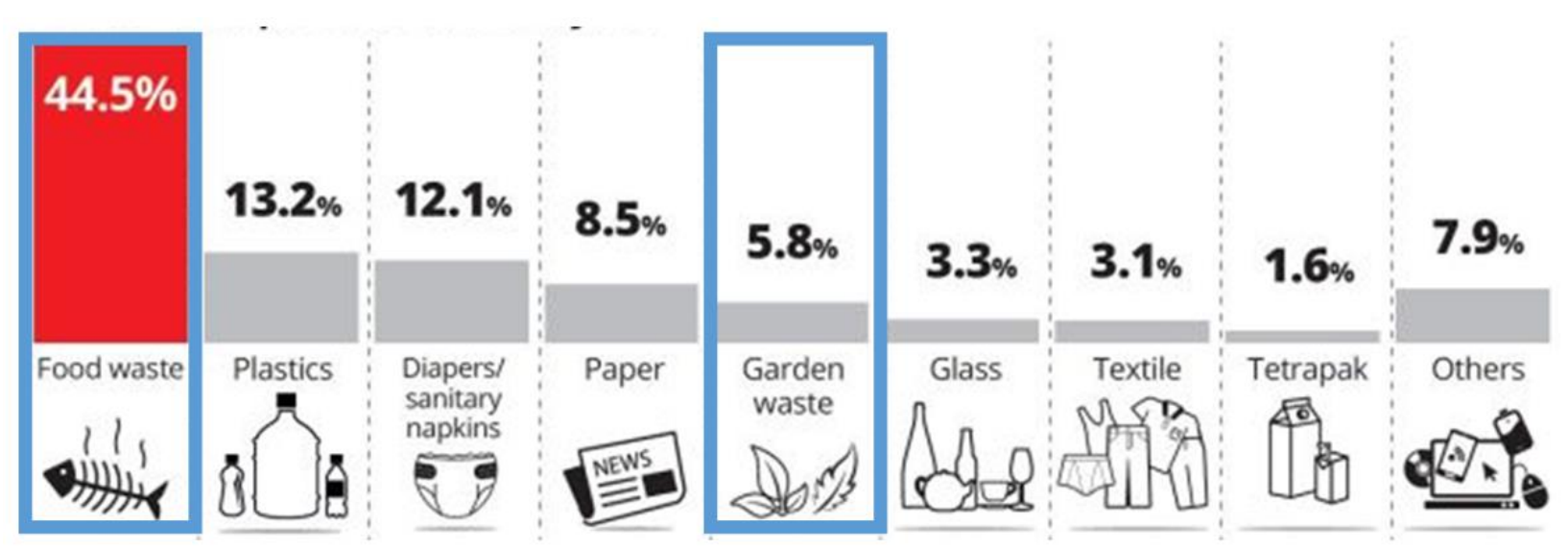

Figure 1. Waste Composition in Malaysia (SWCorp, 2014)

In addition, the uncontrollable waste generation will lead to bigger problem in waste management as well as future sustainable environment. Based on previous study, the waste generation should be predicted in advanced (Loganathan, et al, 2010; Vignesh, et al, 2018; Jamal, et al, 2019). They used time series forecasting analysis in order to forecast the future waste generation scenario. This prediction data could help the management to see the scenario holistically. A several alternative of actions could be implemented for better decision making. Thus, this study is aim to analyse, compare and select the best forecasting model based on the organic waste generation at the administration cafe in UiTM Tapah Campus. The data collection period starts from $4^{\text {th }}$ Mac 2019 until $20^{\text {th }}$ April 2020 from Monday to Friday. There are 2 bins which is located at Administration Cafe 
INTERNATIONAL JOURNAL OF ACADEMIC RESEARCH IN BUSINESS AND SOCIAL SCIENCES Vol. 10, No. 9, 2020, E-ISSN: 2222-6990 @ 2020 HRMARS

in UiTM Tapah Campus as labelled as Bin 1 and Bin 2. The forecasting model is used in order to identify the best fitted model based on data collection at Administration Cafe in UiTM Tapah Campus.

\section{Methodology}

a) Data collection

With a capacity of 200 customers, the administration cafe is located in the middle of the UiTM Tapah campus. Several stalls offer various food and drinks. There are two stalls involved for data collection in this study. The features of the stalls are the preparation of food and the cooking at the stalls. For each stable the researcher provides two bins. The owner of the stalls must separate the waste organics into the bin. Data collection period was during weekdays from 4th Mac 2019 until 20th April 2019. Every Monday to Friday, each bin will be measured using a measurement scale at 5.00PM. The generation of documented organic waste is organized in table form. Figure 2 demonstrates the datagathering process.

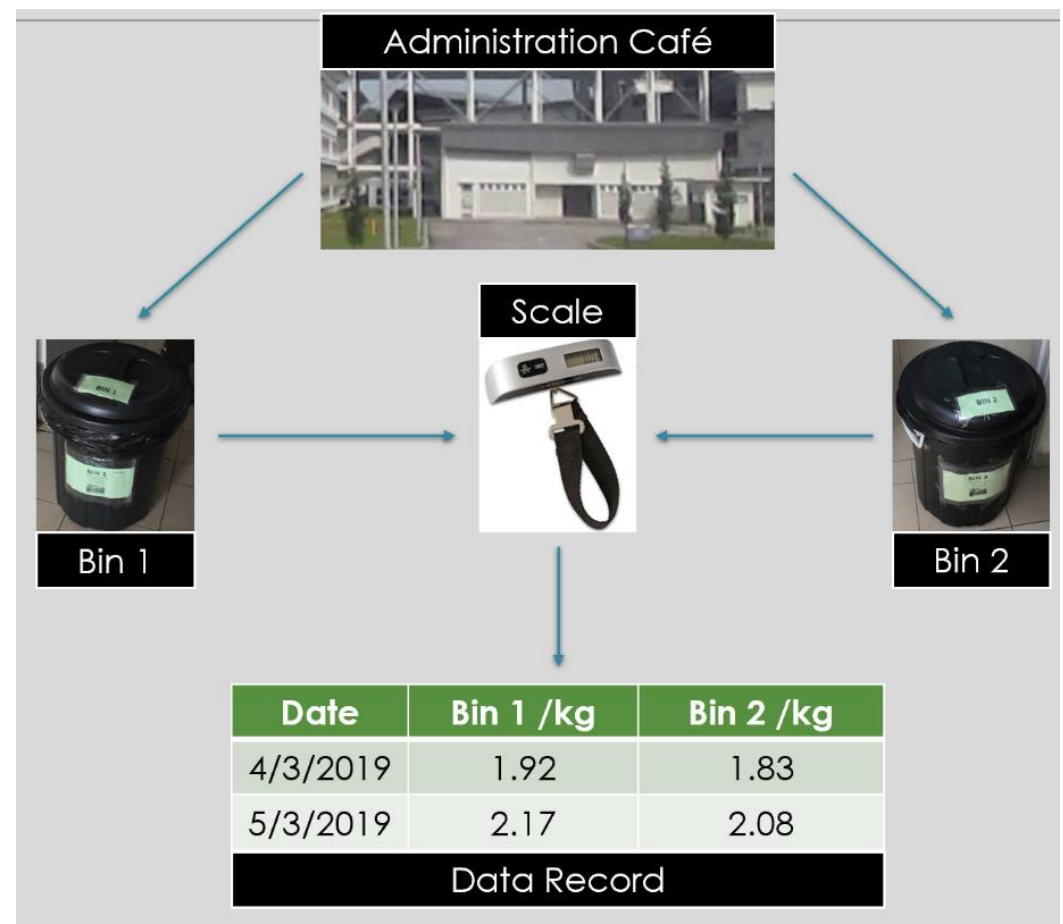

Figure 2. Process of Data Collection

b) Forecasting model

There are three prognostic or forecasting models to be implemented and evaluated in this analysis. These are the Moving Average Model, Model Exponential Smoothing and Model Holt-Winter's. Each model's procedures are as in Table 1 (Lazim, 2013). 
Table 1. Procedure of Forecasting Models

1. Moving Average Model
$F_{t}=\frac{A_{t-1}+A_{t-2}+A_{t-3}+\cdots+A_{t-n}}{n}$
Where,
$F_{t}=$ forecast for the coming period
$n=$ number of periods to be averaged
$A_{t-1}=$ actual occurrence in the past period for up to $n$ periods

2. Exponential Smoothing Model

$F_{t}=\alpha A_{t-1}+(1-\alpha) F_{t-1}$

Where,

$\alpha=$ smoothing constant

$F_{t}=$ forecast for period $t$

$A_{t}=$ actual value in period $t$

3. Holt-Winters Model

$F_{t+k}=E_{t}+k T_{t}$

$E_{t}=w Y_{t-1}+(1-w)\left(E_{t-1}+T_{t-1}\right)$

$T_{t}=v\left(E_{t}-E_{t-1}\right)+(1-v) T_{t-1}$

Where,

$F_{t+k}=$ forecast value $\mathrm{k}$ periods from $t$

$Y_{t-1}=$ actual value for period $t-1$

$E_{t-1}=$ estimated value for period $t-1$

$T_{t}=$ trend for period $t$

$w=$ smoothing constant for estimates

$v=$ smoothing factor for trend

$k=$ number of periods

c) Residual Error of Measurement

In this analysis, the mean square error, mean square error and mean absolute deviation are three types of statistical residual error of the measurements which are source. Comparison of these three residual errors will provide the best fit model for forecasting. Table 2 displays the calculation of these statistical residual measurement errors (Lazim, 2013). 
Table 2. Residual Error of Measurements

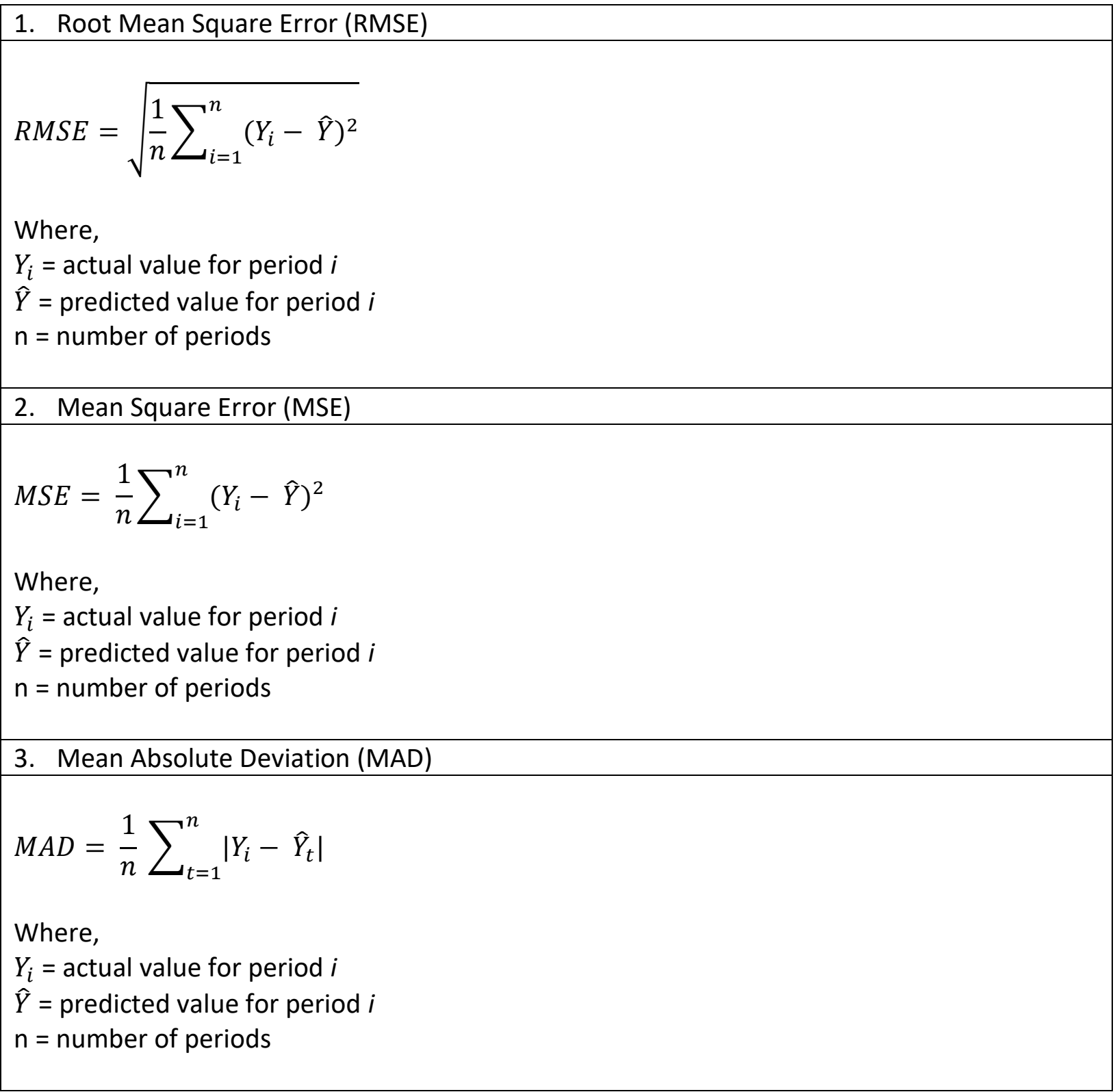

\section{Results and Discussions}

a) Trend of organic waste generation

The organic waste was collected in 7 weeks or 35 days during the weekdays from $4^{\text {th }}$ Mac 2019 until $20^{\text {th }}$ April 2019. Organic waste collection is made Monday through Friday at 5.00pm. Bin 1 and Bin 2 each were calculated using the measuring scale as shown in Figure 2. The trend in the production of organic wastes is shown in Figure 3. Based on Figure 3, Bin 1 (green line) created more organic waste than Bin 2 (yellow line) did. Hence, Stall 1 owner provided numerous food varieties as compared to Stall 2 owner. 
INTERNATIONAL JOURNAL OF ACADEMIC RESEARCH IN BUSINESS AND SOCIAL SCIENCES Vol. 10, No. 9, 2020, E-ISSN: 2222-6990 @ 2020 HRMARS

\section{Organic Waste Generation from Bin 1 and Bin 2 at Administration Cafe, UiTM Tapah Campus}

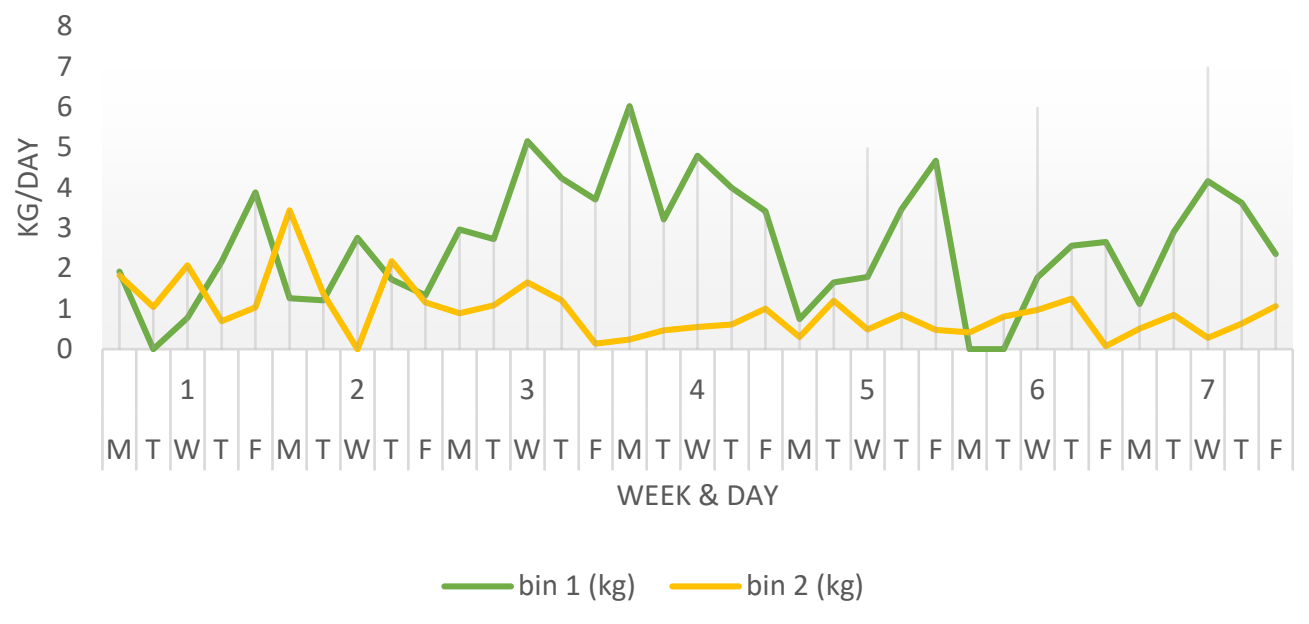

Figure 3. Organic Waste Generation at Administration Cafe in UiTM Tapah Campus

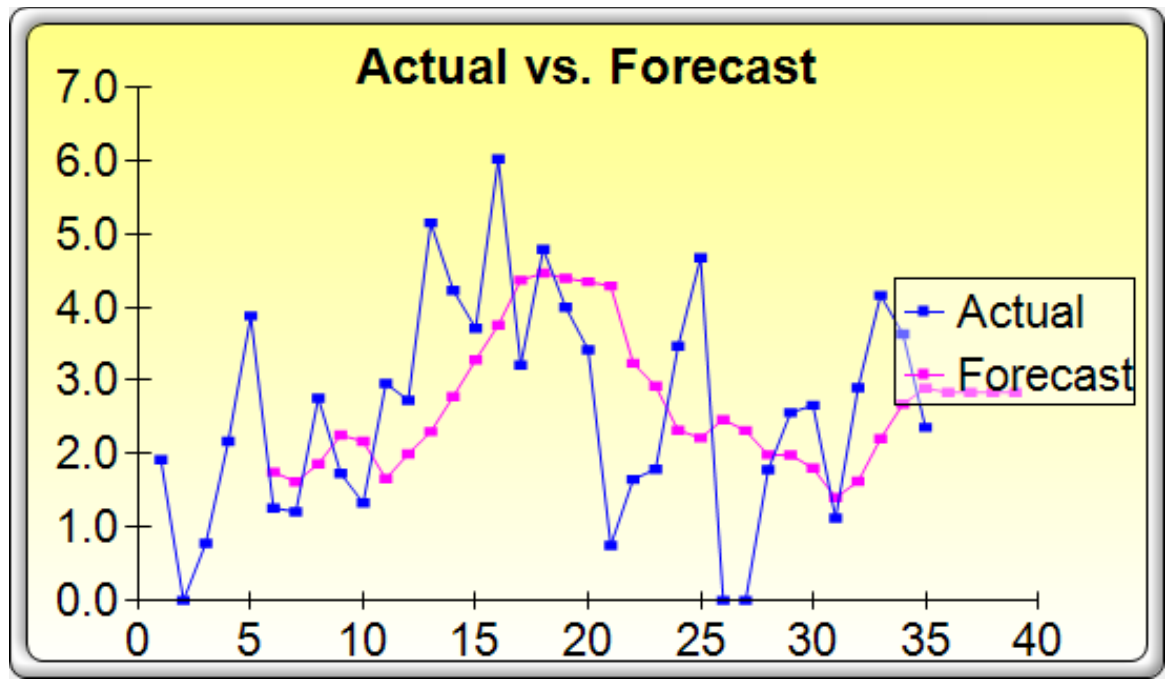

Figure 4. Actual vs Forecast for Bin 1

This study used Risk Simulator Software to do the analysis of the data. This software helps the researcher to overcome time constraints and carry out predictive analysis faster than conventional ones. In Figure 4 and Figure 5, the effects of Bin 1 and Bin 2 indicate where the actual data compared with the predicted data is. 


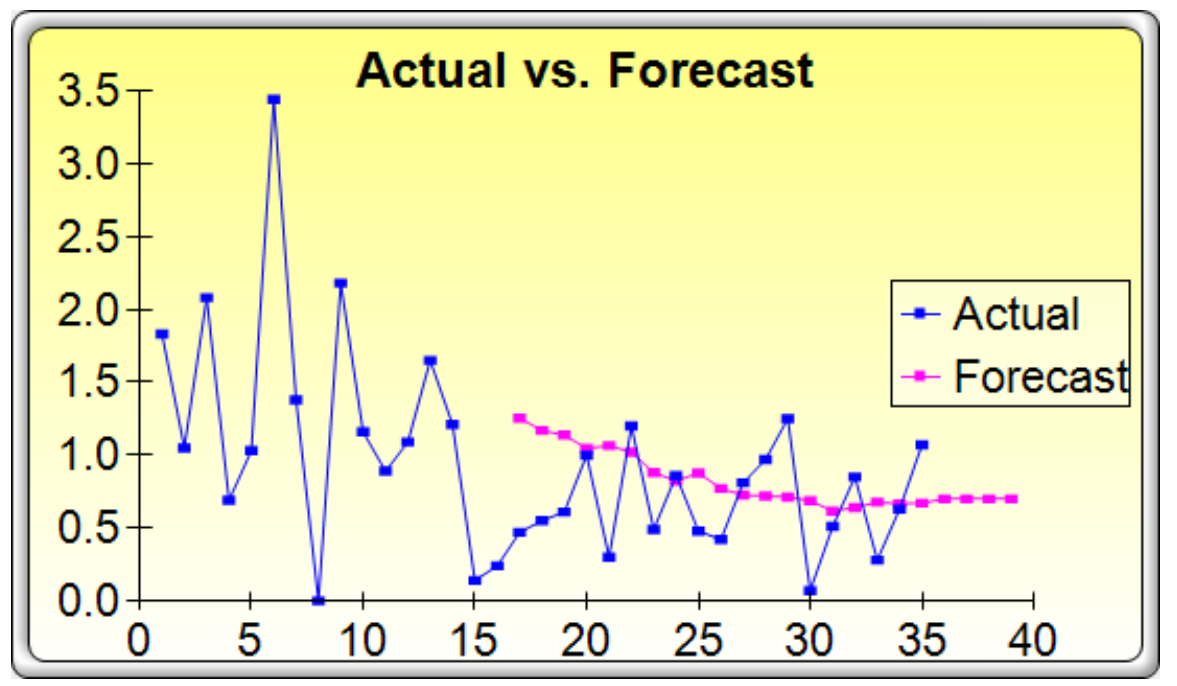

Figure 5. Actual vs Forecast for Bin 2

b) The best forecasting model for Bin 1 and Bin 2 .

Table 3. Forecasting Model Result for Bin 1

\begin{tabular}{|l|l|l|l|}
\hline MODEL & RMSE & MSE & MAD \\
\hline Single Moving Average & 1.4757 & 2.1778 & 1.2088 \\
\hline Double Exponential Smoothing & 1.4778 & 2.1831 & 1.2234 \\
\hline Single Exponential Smoothing & 1.4923 & 2.2271 & 1.2439 \\
\hline Holt-Winter's Additive & 1.5012 & 2.2523 & 1.2074 \\
\hline Double Moving Average & 1.8945 & 3.5893 & 1.5803 \\
\hline
\end{tabular}

Table 3 shows the results for the Bin 1 forecasting model. The best fitted prediction model is based on a comparison of measurement residual errors that were Root Mean Square Error (RMSE), Mean Square Error (MSE), and Mean Absolute Deviation (MAD). For Bin 1 the best fitted model is single moving average (RMSE: 1.4757; MSE: 2.1778; MAD: 1.2088), followed by double exponential smoothing (RMSE: 1.4778; MSE: 2.1831; MAD: 1.2234). In addition, a single exponential smoothing (RMSE: 1.4923; MSE: 2.2271; MAD: 1.2439) and an additive for holt-winter (RMSE: 1.5012; MSE: 2.2523; MAD: 1.2074). Finally, the moving average is double (RMSE: 1.8945; MSE: 3.5893; MAD: 1.5803). 
INTERNATIONAL JOURNAL OF ACADEMIC RESEARCH IN BUSINESS AND SOCIAL SCIENCES Vol. 10, No. 9, 2020, E-ISSN: 2222-6990 @ 2020 HRMARS

Table 4. Forecasting Model Result for Bin 2

\begin{tabular}{|l|l|l|l|}
\hline MODEL & RMSE & MSE & MAD \\
\hline Single Moving Average & 0.4257 & 0.1813 & 0.3545 \\
\hline Double Moving Average & 0.4631 & 0.2144 & 0.3858 \\
\hline Double Exponential Smoothing & 0.6641 & 0.4411 & 0.4981 \\
\hline Single Exponential Smoothing & 0.6756 & 0.4564 & 0.5221 \\
\hline Holt-Winter's Additive & 0.7496 & 0.5620 & 0.5991 \\
\hline
\end{tabular}

The predicted model results for Bin 2 are shown in Table 4. Single moving average is the best fitted model for Bin 2 (RMSE: 0.4257; MSE: 0.1813; MAD: 0.3545), followed by double moving average (RMSE: 0.4631; MSE: 0.2144; MAD: 0.3858). In addition, double exponential smoothing (RMSE: 0.6641; MSE: 0.4411; MAD: 0.4981) and single exponential smoothing (RMSE: 0.6756; MSE: 0.4564), followed. Finally, an additive to the holt-winter (RMSE: 0.7496; MSE: 0.5620; MAD: 0.5991). The results show that moving average model for Bin 1 and Bin 2 can be implemented to forecast future organic waste generation at Administration Cafe at UiTM Tapah Campus.

\section{Conclusion}

This study examined the component exist in time series data of organic waste generation at Administration Cafe in UiTM Tapah Campus. It aims to determine the best fitted forecasting model based on comparing the residual errors measurement using RMSE, MSE and MAD. The best model for Bin 1 is single moving average model while for Bin 2 is also single moving average model. Thus, these models used to determine the predictive organic waste generation in future. This study only focuses on univariate forecasting analysis. For future recommendation, the analysis will add more factors which influent the organic waste generation such as the population at Administration Cafe in UiTM Tapah Campus using econometric forecasting analysis.

\section{Acknowledgement}

This research was supported by the Faculty of Computer and Mathematical Sciences (FSKM). Our sincere gratitude goes to the Universiti Teknologi MARA, Perak Branch, Tapah Campus for providing the financial research. Finally, the authors thank the owner of Stall 1 and Stall 2 at Administration Cafe for their cooperation of data collection.

\section{Corresponding Author}

Faridah Zulkipli, Faculty of Computer and Mathematical Sciences, Universiti Teknologi MARA, Perak Branch, Tapah Campus, Tapah Road, 35400 Perak, MALAYSIA.

Email: faridah7368@uitm.edu.my 
INTERNATIONAL JOURNAL OF ACADEMIC RESEARCH IN BUSINESS AND SOCIAL SCIENCES

Vol. 10, No. 9, 2020, E-ISSN: 2222-6990 @ 2020 HRMARS

\section{References}

Jamal, N. F., Abdul Ghafar, N. M., Chek, A. M. Z., \& Ismail, I. L. (2019). Research of Forecasting on Tourist Arrivals to Malaysia. International Journal of Innovative Technology and Exploring Engineering (IJITEE). 8(12S2). 686-689.

Loganathan, N., \& Ibrahim, Y. (2010). Forecasting international tourism demand in Malaysia using Box Jenkins Sarima application. South Asian Journal of Tourism and Heritage, 3(2), 50-60.

Taha, M. P., \& Wahari, M. D. (2019). Kompedium Pengurusan Sisa Pepejal Malaysia. Solid Waste Corporation and Ministry of Housing and Local Government.

Lazim, M. A. (2013). Introductory business forecasting. A practical approach 3rd edition. University Publication Centre (UPENA).

Solid Waste Corporation (SWCorp), Annual report (2014). Retrieved from http://www.swcorp.gov.my/docfile/laporan-tahunan/2014.pdf.

Vignesh, C., Rameshkumar, M., \& Kumar, A. V. (2018). Time Series Forecasting of Solid Waste Generation in Karur City - Tamil Nadu. SSRG International Journal of Civil Engineering, 5(2), 2023.

Zulkipli, F., Nopiah, Z. M., Basri, N. E. A., Cheng, J. K., \& Khalid, K. I. (2019). Recycle Evaluation using System Dynamics for Solid Waste Management in Malaysia. International Journal of Recent Technology and Engineering (IJRTE). 8(2S11). 657-659.

Zulkipli, F., Nopiah, Z. M., Basri, N. E. A., Cheng. J. K., \& Januri, S. S. (2017). Multilinear regression analysis on solid waste generation quantity in Malaysia towards sustainable development. International Journal of Advanced and Applied Sciences, 4(9), 46-52. 